\title{
Paternal employment in solvent related occupations and adverse pregnancy outcomes
}

\author{
W E DA N I L L ${ }^{1}$ T L V A U GHA N ${ }^{2}$ \\ From the Departments of Environmental Health ${ }^{1}$ and Epidemiology, ${ }^{2}$ School of Public Health and Community \\ Medicine, University of Washington, Seattle, Washington, USA
}

\begin{abstract}
Washington State birth certificates were examined for associations between adverse pregnancy outcomes and paternal employment in solvent exposed occupations. Four cohorts defined by live, singleton births to fathers usually employed as auto body shop workers, painters (construction and maintenance), printers, or fibreglass workers were compared retrospectively with both a systematically selected control cohort and a low solvent exposed, occupationally defined control cohort (paternal electricians). The effects of maternal race and medical illness were controlled by sample restriction; maternal age and gravidity by stratified analysis. There was evidence of increased risk of low birth weight for infants born to fathers employed as body shop workers (relative risk $=1 \cdot 6 ; 95 \%$ confidence interval $=1 \cdot 1-2 \cdot 4)$ or painters $(\mathrm{RR}=1 \cdot 4 ; \mathrm{CI}=0 \cdot 9-2 \cdot 1)$ when compared with the systematically selected controls but not with the electrician controls. The excess risk appeared stronger when only term infants were analysed suggesting a mechanism of growth retardation rather than prematurity. There was no evidence of increased risk among the other exposed cohorts or for other adverse pregnancy outcomes. Several design features limit the interpretation of the findings and confirmation by other studies is needed.
\end{abstract}

Work related birth disorders have generally been regarded as problems related to the occupational experiences of pregnant women. Although far less attention has been paid to the possible effects of paternal toxic exposures, there is increasing evidence that such exposures can influence reproduction and cause abnormalities in offspring. ${ }^{1-3}$

Maternal occupational exposures to organic solvents have been strongly linked with increased risks for both congenital abnormalities and spontaneous abortions. ${ }^{45}$ There are also reports of increased risks associated with solvent exposed paternal occupations. The incidence of anencephalus was examined as part of the Oxford Record Linkage Study and reported to be significantly increased among children whose fathers were employed as printers or as painters at the time of their children's births. ${ }^{6}$ A study using the Danish Register of Congenital Malformations to examine parental occupations of children born with specific malformations found increased risks for malformations of the central nervous system among children born to fathers employed in a broad grouping of solvent exposed jobs and also to those specifically employed as painters (the latter but not the former

Accepted 9 March 1987 was statistically significant). ${ }^{7}$ Studies of childhood cancer and paternal occupation at the time of the child's birth have reported associations between total malignancies and "hydrocarbon related" occupations (motor vehicle mechanics, machinists, miners, and painters) ${ }^{8}$; between Wilms's tumours and mechanics and machinists ${ }^{9}$; and between brain tumours and paternal occupational exposure to paints and solvents. ${ }^{10}$

The present study used data from Washington State birth certificates to evaluate whether paternal employment in occupations potentially involving solvent exposure is associated with adverse pregnancy outcomes.

\section{Methods}

All data were obtained from Washington State records of live births for 1980-3. A retrospective cohort design was used. Four "exposed" cohorts were defined as singleton births with paternal "usual occupation" coded as one of four groups: (1) "body and fender/car painter and renovator," (2) "painter, construction and maintenance," (3) "fibreglassbathtub, boat, plastics," and (4) "pressman and plate printer, printing, litho, (respectively referred to as 
"auto body," "paint," "fibreglass," and "print" cohorts). Two control groups were selected from the remaining singleton birth records. The first was defined by a usual paternal occupation of "electrician"-a skilled manual trade characterised by similar socioeconomic status but relatively low solvent exposures compared with the exposed cohorts. A second "general" control group was selected by systematic sampling (every $n$-th record) of all remaining singleton birth records so as to generate a cohort size similar to the largest exposed cohort: 8541 records were selected.

Records were excluded if the mother was coded as having a chronic medical disorder (diabetes, heart disease, renal disease, hypertension, tumour, or epilepsy). Since maternal race was coded as "white" on $93 \%$ of records, analysis was restricted to records listing white mothers. It was not possible to exclude records involving parents who had been listed on previous records within the study period: $299(7.2 \%)$ of the exposed cohorts' records, $178(6.6 \%)$ of the electrician control records, and $208(12.4 \%)$ of the general control records were excluded by these criteria (final cohort sizes are shown in table 1).

Six outcomes were examined as dichotomous variables: (1) birth weight- "low" ( $<2500 \mathrm{~g})$ or not low $(\geq 2500 \mathrm{~g})$; (2) duration of gestation- "preterm" ( $<266$ days) or "term" (266-293 days) plus "postterm" (294-321 days) combined; $(3,4)$ Apgar score at one and at five minutes-"low" $(0-6)$ or not low (7-10); (5) infant gender; and (6) maternally reported outcome on the most recent prior pregnancyspontaneous fetal loss (including spontaneous abortions and fetal deaths later in gestation) or live birth. Rates of the latter outcome were calculated in relation to the total number of most recent prior pregnancies within each cohort (excluding induced abortions). Because duration of gestation was approximated by the number of days since last normal menses, an upper limit (46 weeks) was selected in an attempt to include pregnancies associated with pseudomenstrual discharge in the first month of gestation and to exclude (in analyses involving duration of gestation) records associated with clinically improbable gestations (3.6\% of records).
Relative risks (RR) for each outcome were calculated for each of the four exposed cohorts in relation to each of the two control cohorts. RR calculated from crude data were compared with those derived from a stratified analysis taking into account various known or suspected risk factors. ${ }^{11}$ Demographic and obstetrical variables examined included maternal and paternal ages, marital status, maternal occupation (whether or not usually employed outside the home), 1980 census tract data (median family income and proportion of families below the poverty level), gravidity, number of prior fetal deaths, and time since last pregnancy. Other than maternal age and gravidity, no single variable was associated with large or consistent confounding effects. Therefore, data were stratified simultaneously by maternal age $(<20,20-29, \geqslant 30$ years) and gravidity $(0,1, \geqslant 2$ prior pregnancies; or 1 , $2, \geqslant 3$ prior pregnancies when examining prior pregnancy outcome) in final calculations of relative risks. Findings were tested for statistical significance using Mantel-Haenszel chi-square statistics. ${ }^{11}$ Ninety five per cent confidence intervals $(95 \% \mathrm{CI})$ were calculated using Miettinen's test based method. ${ }^{12}$

When data for either outcome or independent variables from individual records were not known or not clinically plausible, those records were excluded from analyses involving those variables. Information regarding prior pregnancy outcome was available on $91 \%$ of records listing multigravid mothers. Census tract data were available only for the three predominantly urban counties ( $43 \%$ of records). No more than $5-6 \%$ of records were incomplete for each of the remaining variables.

\section{Results}

The six cohorts were similar in terms of parental ages, but the general control group had fewer married mothers and more mothers employed outside the home than the other cohorts (table 1). There were no important differences between cohorts in obstetric history (number of prenatal visits, number of prior pregnancies, and months since last pregnancy) or census tract family income status. Table 2 shows the

Table 1 Demographic characteristics*

\begin{tabular}{|c|c|c|c|c|c|c|}
\hline & $\begin{array}{l}\text { Auto body } \\
(n=1122)\end{array}$ & $\begin{array}{l}\text { Paint } \\
(n=1299)\end{array}$ & $\begin{array}{l}\text { Fibreglass } \\
(n=648)\end{array}$ & $\begin{array}{l}\text { Print } \\
(n=799)\end{array}$ & $\begin{array}{l}\text { Electrician } \\
\text { control } \\
(n=2529)\end{array}$ & $\begin{array}{l}\text { General control } \\
(n=1469)\end{array}$ \\
\hline $\begin{array}{l}\text { Maternal age } \\
\text { Paternal age } \\
\text { Marriage rate } \\
\text { Maternal employment }\end{array}$ & $\begin{array}{l}24 \cdot 3 \\
(4 \cdot 2)^{*} \\
27 \cdot 1 \\
(5 \cdot 1) \\
95 \cdot 4 \% \\
46 \cdot 6 \%\end{array}$ & $\begin{array}{l}25 \cdot 2 \\
(4 \cdot 6) \\
28 \cdot 2 \\
(5 \cdot 6) \\
95 \cdot 4 \% \\
45 \cdot 4 \%\end{array}$ & $\begin{array}{l}24 \cdot 3 \\
(4 \cdot 4) \\
26 \cdot 7 \\
(5 \cdot 0) \\
97 \cdot 1 \% \\
44 \cdot 4 \%\end{array}$ & $\begin{array}{l}26 \cdot 0 \\
(4 \cdot 8) \\
28 \cdot 4 \\
(5 \cdot 4) \\
98 \cdot 0 \% \\
54 \cdot 2 \%\end{array}$ & $\begin{array}{l}26 \cdot 3 \\
(4 \cdot 3) \\
28 \cdot 8 \\
(5 \cdot 2) \\
98 \cdot 1 \% \\
45 \cdot 5 \%\end{array}$ & $\begin{array}{l}25 \cdot 5 \\
(4 \cdot 9) \\
28 \cdot 4 \\
(5 \cdot 3) \\
88 \cdot 3 \% \\
52 \cdot 8 \%\end{array}$ \\
\hline
\end{tabular}

*Values expressed as mean (with standard deviation in parentheses) or as percentage. 
Table 2 Pregnancy outcome rates among control groups

\begin{tabular}{lcc}
\hline & $\begin{array}{l}\text { Electrician } \\
\text { control }\end{array}$ & $\begin{array}{l}\text { General } \\
\text { control }\end{array}$ \\
\hline Low birth weight & $3.6 \%$ & $3 \cdot 1 \%$ \\
Preterm gestation & $11.3 \%$ & $10.6 \%$ \\
Infant gender (\% female) & $49.2 \%$ & $49.2 \%$ \\
Low 1 minute Apgar score & $11.0 \%$ & $10.9 \%$ \\
Low 5 minute Apgar score & $1.6 \%$ & $1.8 \%$ \\
Fetal loss on last pregnancy & $16.5 \%$ & $18.6 \%$ \\
\hline
\end{tabular}

Rates presented as percentage of current live births or, for "last pregnancy," as percentage of live births plus spontaneous fetal losses (spontaneous abortions and fetal deaths) on most recent prior pregnancy.

rates of the adverse pregnancy outcomes for the two control groups.

The relative risks for each outcome among each exposed cohort in comparison with the general and electrician control groups are shown in tables 3 and 4 , respectively. Whereas several risk estimates were minimally increased, the largest value and the only one which achieved statistical significance was that for low birth weight among the auto body cohort relative to the general control group $(R R=1.6,95 \%$ $\mathrm{CI}=1 \cdot 1-2 \cdot 4)$. Comparisons with the electrician cohort rather than the general cohort generally yielded lower estimates of risk for low birth weight and, to a lesser degree, preterm gestation and slightly higher estimates for prior fetal deaths.

When the risks for low birth weight were examined within gestation categories (table 5), the auto body cohort had increased risks in both gestation categories whereas the paint cohort showed increased risk for low birth weight only when term and post-term births were considered $(\mathrm{RR}=1 \cdot 9,95 \% \mathrm{CI}=1 \cdot 0$ 3.4). Magnitudes of risk estimates for low birth weight within gestation subgroups were again less when determined relative to the electrician cohort rather than to the general cohort. When only the term

Table 3 Risks for adverse pregnancy outcomes relative to general controls*

\begin{tabular}{|c|c|c|c|c|}
\hline & Autobody & Paint & Fibreglass & Print \\
\hline $\begin{array}{l}\text { Low birth weight } \\
\text { Preterm gestation }\end{array}$ & $\begin{array}{l}1 \cdot 6 \\
(1 \cdot 1-2 \cdot 4) \\
1 \cdot 2 \\
(0 \cdot 9-1 \cdot 5)\end{array}$ & $\begin{array}{l}1 \cdot 4 \\
(0 \cdot 9-2 \cdot 1) \\
1 \cdot 0 \\
(0 \cdot 8-1 \cdot 3)\end{array}$ & $\begin{array}{l}1 \cdot 1 \\
(0 \cdot 6-1 \cdot 9) \\
1 \cdot 1 \\
(0 \cdot 8-1 \cdot 4)\end{array}$ & $\begin{array}{l}0.9 \\
(0 \cdot 6-1 \cdot 5) \\
1 \cdot 3 \\
(1 \cdot 0-1 \cdot 6)\end{array}$ \\
\hline $\begin{array}{l}\text { Abnormal } \\
\text { distribution of } \\
\text { infant sex } \\
\text { Low } 1 \text { minute } \\
\text { Apgar score } \\
\text { Low } 5 \text { minute } \\
\text { Apgar score } † \\
\text { Fetal death on } \\
\text { last pregnancy }\end{array}$ & $\begin{array}{c}1 \cdot 0 \\
(0 \cdot 9-1 \cdot 1) \\
1 \cdot 0 \\
(0 \cdot 8-1 \cdot 3) \\
0.7 \\
(0 \cdot 4-1 \cdot 2) \\
1 \cdot 0 \\
(0 \cdot 8-1 \cdot 2)\end{array}$ & $\begin{array}{l}1 \cdot 0 \\
(0 \cdot 9-1 \cdot 1) \\
1 \cdot 0 \\
(0 \cdot 8-1 \cdot 2) \\
1 \cdot 2 \\
(0 \cdot 8-2 \cdot 0) \\
0.9 \\
(0 \cdot 8-1 \cdot 1)\end{array}$ & $\begin{array}{c}0.9 \\
(0.9-1.0) \\
1.2 \\
(1.0-1.6) \\
0.8 \\
(0.4-1.6) \\
0.9 \\
(0.7-1.2)\end{array}$ & $\begin{array}{c}1 \cdot 0 \\
(0.9-1 \cdot 1) \\
0.8 \\
(0.6-1 \cdot 1) \\
0.8 \\
(0.4-1 \cdot 6) \\
1 \cdot 1 \\
(0.8-1 \cdot 3)\end{array}$ \\
\hline
\end{tabular}

* Relative risks have been adjusted for maternal age and gravidity. (95\% Confidence intervals are shown in parentheses.)

tCrude relative risks are presented for low 5 minute Apgar score because of insufficient cases for stratified analysis.
Table 4 Risks for adverse pregnancy outcomes relative to electrician controls*

\begin{tabular}{|c|c|c|c|c|}
\hline & Autobody & Paint & Fibreglass & Print \\
\hline $\begin{array}{l}\text { Low birth weight } \\
\text { Preterm gestation }\end{array}$ & $\begin{array}{l}1 \cdot 3 \\
(0 \cdot 9-1 \cdot 9) \\
1 \cdot 1 \\
(0 \cdot 9-1 \cdot 3)\end{array}$ & $\begin{array}{l}1 \cdot 1 \\
(0 \cdot 7-1 \cdot 5) \\
0 \cdot 9 \\
(0 \cdot 7-1 \cdot 1)\end{array}$ & $\begin{array}{l}0.9 \\
(0.6-1 \cdot 5) \\
1.0 \\
(0.8-1 \cdot 3)\end{array}$ & $\begin{array}{l}0.8 \\
(0 \cdot 5-1 \cdot 2) \\
1 \cdot 1 \\
(0 \cdot 9-1 \cdot 4)\end{array}$ \\
\hline $\begin{array}{l}\text { Abnormal } \\
\text { distribution of } \\
\text { infant sex } \\
\text { Low } 1 \text { minute } \\
\text { Apgar score } \\
\text { Low } 5 \text { minute } \\
\text { Apgar score } \dagger \\
\text { Fetal death on } \\
\text { last pregnancy }\end{array}$ & $\begin{array}{l}1 \cdot 0 \\
(1 \cdot 0-1 \cdot 1) \\
0.9 \\
(0 \cdot 8-1 \cdot 2) \\
0 \cdot 6 \\
(0 \cdot 3-1 \cdot 2) \\
1 \cdot 2 \\
(1 \cdot 0-1 \cdot 4)\end{array}$ & $\begin{array}{l}1 \cdot 0 \\
(0 \cdot 9-1 \cdot 1) \\
1 \cdot 0 \\
(0 \cdot 8-1 \cdot 2) \\
1 \cdot 1 \\
(0 \cdot 7-2 \cdot 0) \\
1 \cdot 1 \\
(0 \cdot 9-1 \cdot 3)\end{array}$ & $\begin{array}{l}1 \cdot 0 \\
(0.9-1 \cdot 0) \\
1 \cdot 2 \\
(0.9-1 \cdot 5) \\
0 \cdot 7 \\
(0.3-1 \cdot 5) \\
1 \cdot 1 \\
(0.9-1 \cdot 4)\end{array}$ & $\begin{array}{l}1 \cdot 0 \\
(0 \cdot 9-1 \cdot 1) \\
0 \cdot 8 \\
(0 \cdot 6-1 \cdot 1) \\
0.8 \\
(0 \cdot 4-1 \cdot 6) \\
1 \cdot 2 \\
(1 \cdot 0-1 \cdot 5)\end{array}$ \\
\hline
\end{tabular}

* Relative risks have been adjusted for maternal age and gravidity. ( $95 \%$ Confidence intervals are shown in parentheses.)

tCrude relative risks are presented for low 5 minute Apgar score because of insufficient cases for stratified analysis.

births (exclusive of the post-term births) were examined, the body shop and paint cohorts each showed risks of 1.8 relative to the general controls $(95 \%$ $\mathrm{CI}=0.9-3 \cdot 8$ and $0 \cdot 9-3 \cdot 6$, respectively).

When records with unstated paternal occupations were excluded from the general control group $(12.4 \%$ of records), the risk estimates for low birth weight among term infants increase slightly to $2 \cdot 0(0 \cdot 9-4 \cdot 2)$ and $1.9(0.9-3.6)$ for the auto body and paint cohorts, respectively.

\section{Discussion}

This study suggests that men employed either as automotive body shop workers or as construction and maintenance painters are at increased risk relative to all other men for fathering children with low birth weight. The increased risk appears to occur primarily in full term births and therefore may involve a mechanism of growth retardation rather than prematurity. There is no evidence of a similar increased risk among the offspring of men employed as fibreglass workers or as printers. There is also no evidence of any increased risk among any of these groups for prematurity, low Apgar scores, or abnormal distribution of infant sex on current births; nor for spontaneous fetal loss on their partners' most recent prior pregnancies.

Table 5 Relative risks for low birth weight relative to general controls (within gestation categories)

\begin{tabular}{lllll}
\hline & Autobody & Paint & Fibreglass & Print \\
\hline Preterm & 1.5 & $1 \cdot 1$ & 0.9 & 0.6 \\
Term plus & $(0.9-2.5)$ & $(0.6-1 \cdot 8)$ & $(0.4-1 \cdot 7)$ & $(0.3-1 \cdot 2)$ \\
post term & 1.6 & 1.9 & $1 \cdot 1$ & 1.0 \\
\hline & $(0.8-3 \cdot 2)$ & $(1.0-3.4)$ & $(0.5-2 \cdot 6)$ & $(0.5-2 \cdot 4)$ \\
\hline
\end{tabular}

All relative risks have been adjusted for maternal age and gravidity. ( $95 \%$ Confidence intervals are shown in parentheses.) 
The findings are not explained by the effects of maternal race, maternal chronic illness, maternal age, gravidity, or multiparous births. No data are available regarding parental dietary habits, alcohol history, or tobacco use. Although median census tract incomes were similar across cohorts, a lower socioeconomic status of the general control group is suggested by relatively higher rates in that group of non-marriage, maternal non-employment, and missing paternal data. This might introduce a conservative bias in risk estimates relative to the general control group.

The use of birth records as a source of data can produce misclassification of exposures by a number of mechanisms. Paternal occupation is only a crude index of actual chemical or physical workplace exposures. Fathers with the same occupational code will not necessarily have the same types or degrees of exposures. Furthermore the listing for the father's "usual" occupation may not accurately represent paternal exposure at a physiologically relevant time. Errors can occur in the actual coding of occupations, but this is probably not common with straightforward job titles such as those studied here. ${ }^{13}$ Each of these misclassification effects would tend to bias estimates of risk towards unity.

The completeness and accuracy of recording of current reproductive outcomes on birth certificates varies with each outcome. Recording of birth weight is relatively reliable. ${ }^{14}$ There were no missing values for birth weight in this data set. Duration of gestation was calculated in this study as the number of days since the mother's last normal menses. Approximately $7 \cdot 2 \%$ of records were excluded from analyses of gestation because of clinically improbable values ( $>46$ weeks) or missing values. Misclassification of calculated gestation duration is unlikely to be related to paternal occupation but analyses involving duration of gestation must be interpreted cautiously.

A control group defined by a "low exposure" paternal occupational was used in an attempt to control for socioeconomic status, and its use yielded lower estimates of relative risk for low birth weight among the exposed cohorts. Comparisons with the electrician cohort may provide more complete matching of socioeconomic variables than do comparisons with the general control group; however, one does not see a similar pattern in the analyses involving other birth outcomes which are also susceptible to socioeconomic influences. An alternative explanation is that whatever pathological mechanisms might operate in the auto body and paint cohorts may also occur in lesser degree among the electrician group. A third possible explanation is that this pattern occurred by chance and has no relevance to wider populations.

An increased risk for low birth weight has major implications for the health of newborns. Low birth weight has been related to increased neonatal and postneonatal mortality as well as to childhood morbidity. ${ }^{15-17}$ These effects are primarily associated with very low birth weights $(<1500 \mathrm{~g})$; but neonatal mortality rates are increased with (and inversely related to) all weights under $2500 \mathrm{~g} .{ }^{17}{ }^{18}$ The fact that a paternal exposure might have influenced fetal growth at all also serves as an indicator that other less visible or less frequent adverse effects might occur.

Olsen and Rachootin examined the relation between birth weight and parental exposure to solvents. ${ }^{18}$ Through the records of a Danish hospital, they identified and gave self administered questionnaires to 2620 couples who during a two year period delivered a healthy child with a gestational age of 258 days or more. Solvent exposure was classified dichotomously by whether or not there had been contact at least once a week for at least one year. They found no evidence that maternal or paternal solvent exposure influenced either mean birth weight or the occurrence of low birth weight (defined as $<3100 \mathrm{~g}$ ). There was also no association between mean birth weight and whether parents' jobs during pregnancy or their longest held jobs were classified as generally having exposure to organic solvents. This study, however, used relatively broad definitions of low birth weight and solvent exposure; and because of its case-control design, it included only a small number of parents who had job titles classified as routinely solvent exposed. These differences may account for the conflicting results.

The present study offers little explanation for what mechanisms might be involved in the apparent relation between low birth weight and paternal employment as a painter or as an auto body worker. Possible routes of exposure might involve male mediated maternal exposure or actual paternal toxicity. The exposed cohorts were initially selected on the basis of their known routine exposures to organic solvents but other chemical or physical agents might be the aetiological agents. Since several comparisons were made in this study, it is possible that the few statistically significant findings are actually chance results associated with multiple testing. The findings need to be confirmed by other studies before further interpretation is possible.

We thank Andrew Olshan for his technical help and the Department of Social and Health Services of the State of Washington for providing access to the birth certificate data files.

This research was supported in part by general research and teaching funds from the State of Washington through the University of Washington. 


\section{References}

1 Pearn JH. Teratogens and the male: an analysis with special reference to herbicide exposure. Med J Aust 1983;2:16-20.

2 Fabro S, Brown NA, Scialli AR, eds. Paternally-induced adverse pregnancy effects. Reproductive Toxicology 1984;3:13-6.

3 Brown NA. Are offspring at risk from their father's toxins? Nature 1985;316:110.

4 Hemminki K, Vineis P. Extrapolation of the evidence on teratogenicity of chemicals between humans and experimental animals: chemicals other than drugs. Teratogenesis Carcinog Mutagen 1985;5:251-318.

5 Fabro S, Brown NA, Scialli AR, eds. Is there a fetal solvent syndrome? Reproductive Toxicology 1983;2:17-20.

6 Fedrick J. Anencephalus in the Oxford record linkage study area. Dev Med Child Neurol 1976;18:643-56.

7 Olsen J. Risk of exposure to teratogens amongst laboratory staff and painters. Dan Med Bull 1983;30:24-8.

8 Fabia J, Thuy DT. Occupation of father at time of birth of children dying of malignant diseases. Br J Prev Soc Med 1974;28:98-100.

9 Kwa S-L, Fine LJ. The association between parental occupation and childhood malignancy. J Occup Med 1980;22:792-4.
10 Peters JM, Preston-Martin S, Yu MC. Brain tumors in children and occupational exposure of parents. Science 1981;213:235-7.

11 Mantel N, Haenszel W. Statistical aspects of the analysis of data from retrospective studies of disease. J Natl Cancer Inst 1959;22:719-48.

12 Miettinen OS. Estimability and estimation in case-referent studies. Am J Epidemiol 1976;103:226-35.

13 Vaughan TL, Daling JR, Starzyk PM. Fetal death and maternal occupation: an analysis of birth records in the state of Washington. J Occup Med 1984;26:676-8.

14 Polednak AP, Janerich DT. Uses of available record systems in epidemiologic studies of reproductive toxicology. Am J Ind Med 1983;4:329-48.

15 McCormick MC. The contribution of low birth weight to infant mortality and childhood morbidity. N Engl J Med 1985; 312:82-90.

16 Spurlock CW, Hinds MW, Bergeisen GH. Birthweight-specific neonatal mortality rates-Kentucky. $M M W R$ 1985;34:487-8.

17 Anonymous. National birthweight-specific infant mortality surveillance: preliminary analysis-United States, 1980. MMWR 1986:35:269-73.

18 Olsen J, Rachootin P. Organic solvents as possible risk factors of low birthweight. J Occup Med 1983;25:854-5. 